\title{
Trichotillomania occurs during the COVID-19 pandemic in an adolescent
}

\author{
Xue Wang $^{1} \cdot$ Bin Zhang ${ }^{1,2}$ (D)
}

Received: 30 November 2021 / Accepted: 17 January 2022 / Published online: 28 February 2022

(c) Children's Hospital, Zhejiang University School of Medicine 2022

\begin{abstract}
A13-year-old boy presented with a 1-week history of hair loss on the scalp. Physical examination revealed linear alopecia with the normal scalp (Fig. 1a). Trichoscopy examination revealed irregular black dots, flame hair, and V sign (Fig. 1b). After a detailed inquiry, the patient finally admitted that he had pulled his hair down every night. The boy was then referred to the Psychology Clinic of the hospital. In the psychiatry visit, psychological scales (Children's YaleBrown Obsessive-Compulsive Scale, Screen for Child Anxiety Related Emotional Disorders, Depression Self-Rating Scale for Children and Child Behavior Checklist) indicated a high level of anxiety due to isolation during the COVID19 epidemic. A diagnosis of trichotillomania was made.
\end{abstract}

Trichotillomania is a compulsive desire or habit to pluck the hair, which is frequently associated with anxiety or depression [1]. Pathulos et al. reported that the COVID-19 pandemic led to hair-pulling symptoms increased in the patients with the body-focused repetitive behaviors that include trichotillomania, nail biting, and skin picking [2]. In additional, three cases of trichotillomania in children were reported which might be induced by bored mental, because the schools closed in the COVID-19 outbreak [3]. In our case, long-time separation from parents and lack of outdoor activity during the COVID-19 pandemic could be the cause. After 4 weeks of behavior modification therapy in the Psychology Clinic, the patient's alopecia achieved full remission (Fig. 1c). We
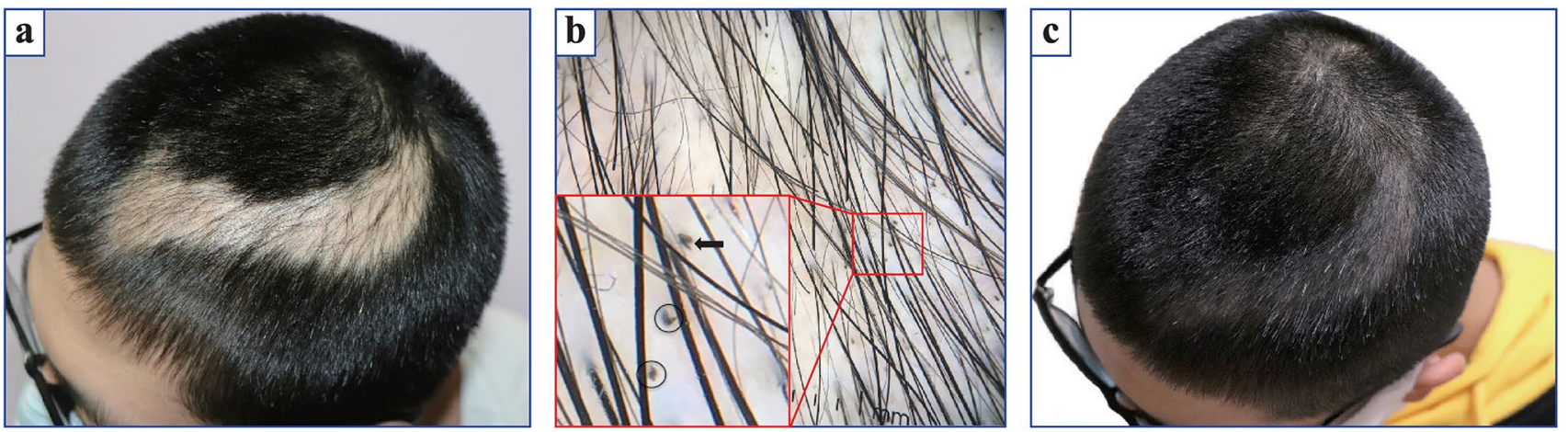

Fig. 1 Clinical manifestations of the patient's first visit to the clinic (a). The trichoscopy (Dermlite DL-4, 3Gen, polarized contact mode) examination revealed several irregular black dots in the whole view, partially enlarged view showed flame hair (circle) and V sign (arrow) (b). The manifestations of the patient after completing the behavior modification therapy (c)

Bin Zhang

binzhang@mail.ccmu.edu.cn

1 Department of Dermatology, National Center for Children's Health, Beijing Children's Hospital, Capital Medical University, No. 56 Nanlishi Road, Xi Cheng District, Beijing 100045, China

2 Affiliated Children's Hospital, Zhengzhou University, Henan Children's Hospital, Zhengzhou Children's Hospital, Zhengzhou, China 
Table 1 The psychological assessment pro- and post-intervention

\begin{tabular}{|c|c|c|c|}
\hline Tools & Pro- & Post- & Explanations \\
\hline CBCL & 34 & 8 & $\begin{array}{l}\text { Decareased emotional and behavioral } \\
\text { problems }\end{array}$ \\
\hline CY-BOCS & 23 & 11 & $\begin{array}{l}\text { Reduced obsessive-compulsive symp- } \\
\text { toms }\end{array}$ \\
\hline SCARED & 61 & 13 & Reduced anxiety symptoms \\
\hline DSRSC & 14 & 17 & Increased depressive symptoms \\
\hline
\end{tabular}

$C B C L$ child behavior checklist; $C Y$-BOCS Children's Yale-Brown obsessive-compulsive scale; SCARED screen for child anxiety-related emotional disorders; DSRSC depression self-rating scale for children

also summarize detailed psychological assessment scores before and after interventions in Table 1 . This case reminded us that more attention should be paid to the mental health of children affected by the COVID-19 pandemic.

Acknowledgments The authors would like to acknowledge Ying Li (Department of Psychology in Beijing Children's Hospital of Capital Medical University) and the pediatric patient and his parents.

Author contributions $\mathrm{XW}$ : software and writing —original draft preparation; BZ: reviewing and editing.

Funding The Special Fund of the Pediatric Medical Coordinated Development Center of Beijing Hospitals Authority (XTZD20180502) and Beijing Natural Science Foundation (7222058).
Data availability statement Our article did not generate any research data.

\section{Declarations}

Conflict of interest No financial or non-financial benefits have been received or will be received from any party related directly or indirectly to the subject of this article.

Ethical approval This study has been approved by Ethical Committee of Beijing Children's Hospital.

Consent for publication Written consent for publication of the case details together with imaging or videos have been obtained from the parents.

\section{References}

1. Grant JE, Chamberlain SR. Trichotillomania. Am J Psychiatry. 2016;173:868-74.

2. Pathulos JT, Olson SJ, Idnani A, Farah RS, Hordinsky MK, Widge AS. Cross-sectional survey examining skin picking and hair pulling disorders during the COVID-19 pandemic. J Am Acad Dermatol. 2021;84:771-3.

3. Öner Ü. Children with trichotillomania in COVID-19 outbreak. J Cosmet Dermatol. 2021;20(7):1967-8.

Publisher's Note Springer Nature remains neutral with regard to jurisdictional claims in published maps and institutional affiliations. 